\title{
Review Article \\ Calcium Channel Expression and Applicability as Targeted Therapies in Melanoma
}

\author{
A. Macià, ${ }^{1}$ J. Herreros, ${ }^{1}$ R. M. Martí, ${ }^{1,2}$ and C. Cantí ${ }^{1}$ \\ ${ }^{1}$ University of Lleida-IRBLleida, 25198 Lleida, Spain \\ ${ }^{2}$ Department of Dermatology, University Hospital Arnau de Vilanova, 25198 Lleida, Spain
}

Correspondence should be addressed to C. Cantí; c.canti@mex.udl.cat

Received 17 October 2014; Revised 15 December 2014; Accepted 15 December 2014

Academic Editor: Ajit S. Narang

Copyright (C) 2015 A. Macià et al. This is an open access article distributed under the Creative Commons Attribution License, which permits unrestricted use, distribution, and reproduction in any medium, provided the original work is properly cited.

\begin{abstract}
The remodeling of $\mathrm{Ca}^{2+}$ signaling is a common finding in cancer pathophysiology serving the purpose of facilitating proliferation, migration, or survival of cancer cells subjected to stressful conditions. One particular facet of these adaptive changes is the alteration of $\mathrm{Ca}^{2+}$ fluxes through the plasma membrane, as described in several studies. In this review, we summarize the current knowledge about the expression of different $\mathrm{Ca}^{2+}$ channels in the plasma membrane of melanoma cells and its impact on oncogenic Ca ${ }^{2+}$ signaling. In the last few years, new molecular components of $\mathrm{Ca}^{2+}$ influx pathways have been identified in melanoma cells. In addition, new links between $\mathrm{Ca}^{2+}$ homeostasis and specific cell processes important in melanoma tumor progression have been unveiled. Thus, not only do $\mathrm{Ca}^{2+}$ channels appear to have a potential as prognostic markers, but their pharmacological blockade or gene silencing is hinted as interesting therapeutic approaches.
\end{abstract}

\section{Introduction}

Ionized calcium $\left(\mathrm{Ca}^{2+}\right)$ is a ubiquitous second messenger that mediates several physiological functions, such as cell proliferation, survival, apoptosis, migration, and gene expression. The concentration of $\mathrm{Ca}^{2+}$ in the extracellular milieu is $1-2 \mathrm{mM}$ whereas, at rest, intracellular $\mathrm{Ca}^{2+}$ is maintained at about $100 \mathrm{nM}$ [1]. Specific $\mathrm{Ca}^{2+}$-transporters and $\mathrm{Ca}^{2+}$ binding proteins are used by cells to extrude $\mathrm{Ca}^{2+}$ through the plasma membrane, transport $\mathrm{Ca}^{2+}$ into the intracellular reservoirs, and buffer cytosolic $\mathrm{Ca}^{2+}[2,3]$. Conversely, there is a diversity of $\mathrm{Ca}^{2+}$ channels in the plasma membrane allowing $\mathrm{Ca}^{2+}$ entry into the cytosol. $\mathrm{Ca}^{2+}$ influx may cross-talk with $\mathrm{Ca}^{2+}$ channels present in the endoplasmic reticulum (ER), resulting in localized $\mathrm{Ca}^{2+}$ elevations that are decoded through a variety of $\mathrm{Ca}^{2+}$-dependent effectors $[1,4]$.

It has been long known that external $\mathrm{Ca}^{2+}$ is needed to induce cell proliferation and cell cycle progression in mammalian cells [5]. Some studies indicate a requirement of $\mathrm{Ca}^{2+}$ influx to induce a G1/S-phase during the cell cycle process $[6,7]$. However, in cancer cells such requirement is modulated by the degree of cellular transformation, so that neoplastic or transformed cells continue proliferating in $\mathrm{Ca}^{2+}$-deficient media [8].

Several types of $\mathrm{Ca}^{2+}$ channels have been involved in cell cycle progression: transient receptor potential melastatin (TRPM), transient receptor potential vanilloid (TRPV), Transient Receptor Potential Canonical (TRPC), components of the store-operated calcium entry (SOCE) pathway such as $\mathrm{Ca}^{2+}$ influx channel (ORAIl) and endoplasmic $\mathrm{Ca}^{2+}$ depletion sensor (STIM1), and voltage-gated calcium channels (VGCCs) [5]. Through the use of in vitro models, a role for TRPC1, ORAIl, or STIM1 in $\mathrm{Ca}^{2+}$ signaling changes associated with the proliferation of endothelial cells has been uncovered $[9,10]$. In addition, L- and T-type VGCCs have been shown to be upregulated during the S-phase in vascular smooth muscle cells [11, 12]. T-type channels appear to be specially suited for promoting cell cycle progression by virtue of their fast activation upon weak depolarization. This feature enables transient elevations of cytosolic $\mathrm{Ca}^{2+}$ in nonexcitable 
cells that signal to favor mitotic progression through direct binding of $\mathrm{Ca}^{2+}$ to intracellular effectors such as calmodulin (CaM) [4].

$\mathrm{Ca}^{2+}$ influx also plays an important role in tumor growth. Commonly, cancer cells present alterations of $\mathrm{Ca}^{2+}$ fluxes across the plasma membrane that reflect changes in the expression, subcellular localization, and/or function of different types of $\mathrm{Ca}^{2+}$ channels $[13,14]$. Among them, the expression of different members of the TRP family has been shown to be altered in cancer cells. Particularly, TRPC 3 is induced in breast and ovarian epithelial tumors, and TRPC6 is highly expressed in cancer of breast, liver, stomach, and esophagus and glioblastoma [14]. Similarly, the expression of TRPV1 and TRV4 is elevated in human hepatoblastoma and breast cancer cells, respectively $[14,15]$, and the expression level of TRPV6 correlates with tumor progression in prostate, thyroid, colon, ovarian, and breast cancers [16]. Moreover, TRPM8 is overexpressed in different carcinomas and has been proposed to be a "prooncogenic receptor" in prostate cancer cells $[16,17]$.

In addition, depletion of $\mathrm{Ca}^{2+}$ from the ER may drive tumor growth by inducing $\mathrm{Ca}^{2+}$ influx through the plasma membrane, as the expression of the SOCE canonical components STIM1 and ORAI1 is augmented in various cancer types, including breast cancer, glioblastoma, melanoma, and esophageal carcinoma (reviewed in $[1,14]$ ).

VGCCs are also involved in cancer progression by generating oscillatory $\mathrm{Ca}^{2+}$ waves that favor cell cycle progression [18]. Heightened levels of L-type channel $\mathrm{Ca}_{\mathrm{v}} 1.2 \mathrm{mRNA}$ have been reported in colorectal cancer [19]. Several studies have confirmed the increased expression of T-type $\mathrm{Ca}_{\mathrm{v}} 3.2$ channels in breast, colon, prostate, ovarian, esophageal, and colon cancers and in glioblastoma, hepatoma, and melanoma [20]. However, hypermethylation of the T-type channel gene CACNA1G (that encodes the $\mathrm{Ca}_{\mathrm{v}} 3.1$ isoform) occurs in different tumors including colon, pancreatic, and gastric cancer, suggesting that it acts as a tumor suppressor [21].

Cell physiology aspects other than proliferation are dependent on $\mathrm{Ca}^{2+}$ influx too. Through cell migration, $\mathrm{Ca}^{2+}$ signaling is involved in the directional sensing of the cells, in the redistribution and traction force of the cytoskeleton and in the repositioning of new focal adhesions [22, 23]. Cell migration is an early prerequisite for tumor metastasis with enormous impact on patient prognosis [23]. Members of the same $\mathrm{Ca}^{2+}$ channel families involved in tumor growth have been implicated in cancer cell migration and metastasis, such as TRP channels [24-26], STIM/ORAI-mediated SOCE [2730], and T-type VGCCs [31, 32]. For example, TRPM7 has a promigratory effect on human nasopharyngeal carcinoma and its expression is related to metastasis formation [24], being a marker of poor prognosis in human breast cancer [25]. Nevertheless, TRPM1 expression in mice melanoma cells is reduced during metastasis [26]. Yang et al. provided evidence for the role of STIM1 and ORAI1 in the migration of the breast cancer cells using pharmacological blockers or siRNA [28]. The significance of STIM1 in focal adhesion and cell migration is extended to cervical cancer and hepatocellular carcinoma $[29,30]$. Furthermore, it has been shown that
T-type calcium channels regulate cell motility and migration in fibrosarcoma cells [31]. Conversely, Zhang et al. provided evidence for T-type channel blockers as dual inhibitors of proliferation and migration of human glioblastoma cells [32].

Finally, cell fate is also dependent on $\mathrm{Ca}^{2+}$ influx and its molecular machinery. Both the pharmacological blockade and the siRNA-mediated silencing of TRPM8 channels have been shown to induce the apoptotic death of prostate cancer cells [33], indicating a critical role for these channels in $\mathrm{Ca}^{2+}$ homeostasis maintenance. It has been suggested that TRPM8 could regulate either proliferation or apoptosis mechanism in prostate cells, depending on its intracellular localization [34]. Moreover, TRPV1 has been proposed as a useful target for killing malignant cells, since mitochondrial function was inhibited and apoptosis was induced in pancreatic cancer cells treated with a vanilloid analogue $[8,35]$. VGCCs also play a relevant role in the survival of cancer cells. We have recently reported that $\mathrm{T}$-type pharmacological blockers induce apoptosis in melanoma cells, in addition to reducing its proliferation [36]. Importantly, in the referred work the pharmacological results were backed up by siRNA-mediated silencing of $\mathrm{Ca}_{\mathrm{v}} 3.1$ and $\mathrm{Ca}_{\mathrm{v}} 3.2$ T-type channel isoforms. Likewise, Valerie et al. found that inhibition of T-type channels by a selective antagonist or siRNA-mediated gene knockdown not only reduced glioma cell viability but also induced apoptosis. These effects were reached via inhibition of the mTORC2/Akt pathway followed by a reduction in the phosphorylation of antiapoptotic Bad [37].

Hereon, this review will discuss the current knowledge about the role of different $\mathrm{Ca}^{2+}$ channels expressed in the plasma membrane of melanoma cells, as well as the $\mathrm{Ca}^{2+}$ signaling pathways involved during tumorigenesis and tumor progression.

\section{Calcium Channels in Melanoma}

Cutaneous melanoma is a malignant skin cancer that arises from transformed melanocytes de novo or from dysplastic, congenital, or common nevi [50]. Melanoma is the most dangerous form of skin cancer, and its incidence is steadily increasing worldwide. In spite of being the subject of intense laboratory investigations and numerous clinical trials, the prognosis of metastatic melanoma is still poor. New treatment strategies such as immunotherapy and specific gene therapy are currently under investigation.

\subsection{Transient Receptor Potential Melastatin (TRPM) in} Melanoma. TRP channels are known to regulate melanocyte physiology, particularly members of the TRPM subfamily [38]. Untransformed melanocytes express the full-length TRPM1 mRNA along with an alternative splicing variant (TRPM1-s) [51]. TRPM1 function appears to be critical to normal melanocyte pigmentation and melanogenesis, and thus this channel is a potential target for pigmentation disorders [52].

TRPM1 was first discovered in B16 mouse melanoma cell lines as a result of a differential display analysis [26]. This channel is strongly expressed in poorly metastatic B16 cells 


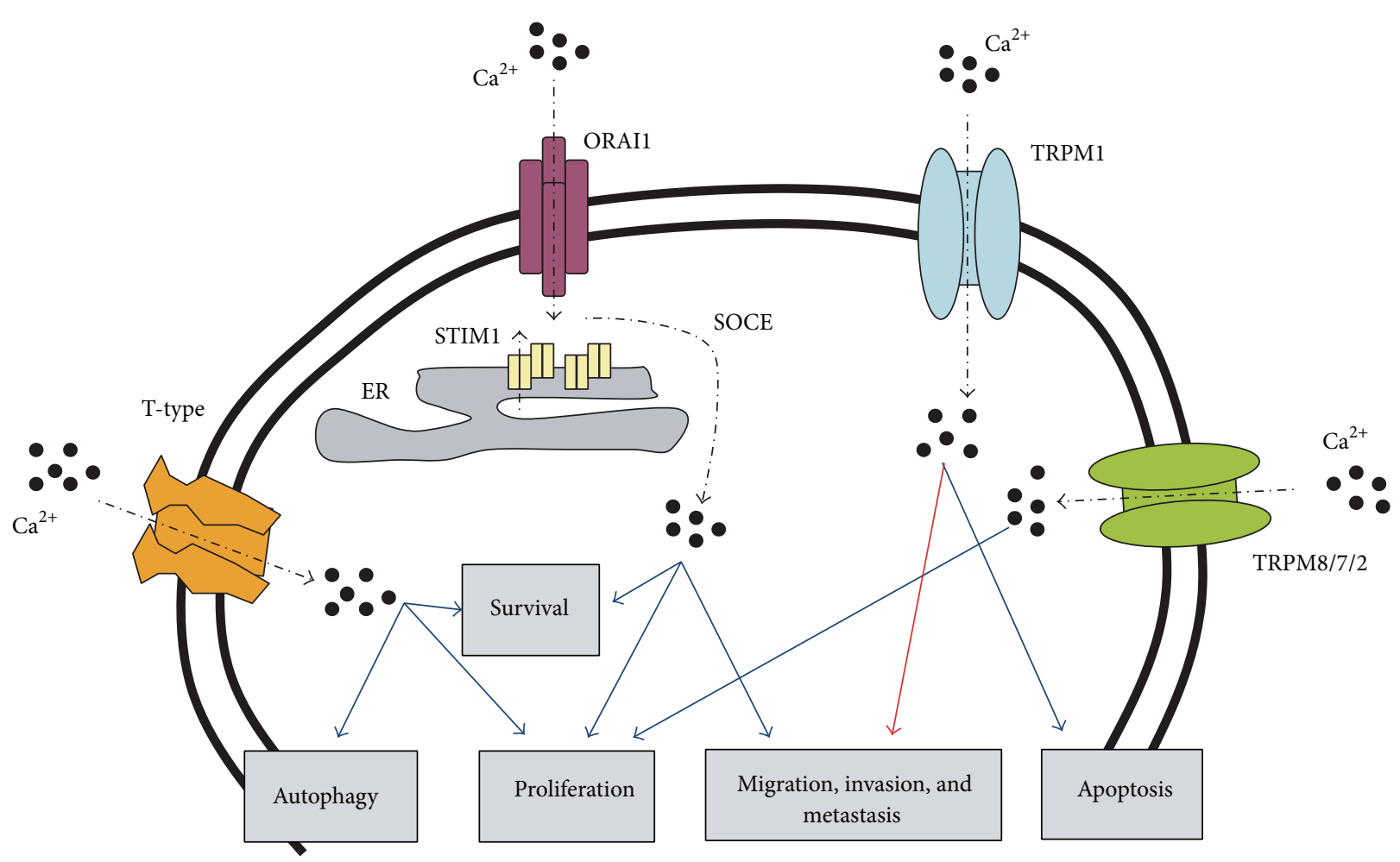

FIGURE 1: $\mathrm{Ca}^{2+}$-influx pathways and their physiological functions in melanoma cells. Blue line indicates positive regulation. Red line indicates inhibition.

and expressed at reduced levels in the highly metastatic B16F10 variant [26]. Moreover, in formalin-fixed tissue sections benign nevi were found to express high levels of TRPM1 that showed a low expression in primary melanomas whereas the full-length transcripts were not detected in melanoma metastases (but several short fragments of TRPM1) [26, 39]. As a matter of fact, several studies point to TRPM1 as a tumor suppressor in melanoma cells, as its loss of expression correlates with melanocytic tumor progression, metastatic potential, tumor thickness, and overall melanoma tumor aggressiveness (Figure 1; Table 1) [16, 26, 38-41]. In line with this, it has been suggested that the levels of TRPM1 mRNA can be used to predict the future development of metastatic melanoma [16, 38].

The regulation of TRPM1 gene expression has been extensively investigated. It has been proposed that TRPM1 expression in melanocytes and melanoma cells is regulated by a promoter region of the gene that contains four microphthalmia transcription factor (MITF) binding sites. Several groups demonstrated that MITF directly regulates the expression of TRPM1 in vitro and in vivo during melanoma progression [38, 42, 53, 54].

TRPM1 gene encodes both TRPM1 mRNA and miR-211 which is coded by the sixth intron of the gene. TRPM1 and miR-211 share the same promoter and are coregulated by MITF. Similar to TRPM1 protein, miR-211 is highly expressed in melanocytes and nevi and is reduced in melanoma cells $[55,56]$. Consistently, overexpression of miR-211 exhibited significant growth inhibition and reduced migration and invasion in melanoma cells $[38,55-57]$.
Melanoma cells also express functional TRPM8 channels that produce a sustainable $\mathrm{Ca}^{2+}$ influx upon activation by menthol as agonist [43]. Strikingly, in this study the viability of melanoma cells was dose-dependently depressed in the presence of menthol, indicating that these channels underlie tumor progression via the $\mathrm{Ca}^{2+}$ handling pathway and suggesting TRPM8 $\mathrm{Ca}^{2+}$ channels as novel targets of drug development for malignant melanoma (Figure 1; Table 1).

Another member of the TRP family, TRPM2, is an ion channel capable of conferring susceptibility to cell death upon oxidative stress [58]. Quantitative RT-PCR experiments revealed that two antisense transcripts (TRPM2-AS and TRPM2-TE) from the TRPM2 gene were upregulated in melanoma cells and that their activation was linked to the hypermethylation of a shared CpG island. Moreover, knockdown of TRPM2-TE (proposed as a dominant-negative transcript) increased the vulnerability of melanoma cells to undergo apoptosis and necrosis, and overexpression of wildtype TRPM2 in melanoma cells leads to a faster proliferation (Figure 1; Table 1) [38, 44].

Finally, TRPM7 receptor has a protective and detoxifying function in normal and malignant melanocytes. In contrast to TRPM1, TRPM7 is highly expressed in metastatic melanoma (Figure 1; Table 1) [38, 45].

2.2. Store-Operated $\mathrm{Ca}^{2+}$ Entry (SOCE) in Melanoma. $\mathrm{Ca}^{2+}$ storage in the ER is an essential indicator of the proliferative, metabolic, and apoptotic status of cells. The retrograde signaling process from $\mathrm{ER} \mathrm{Ca}^{2+}$ depletion to SOCE activation has 
TABLE 1: Expression and physiological role of calcium channels in melanoma.

\begin{tabular}{|c|c|c|c|}
\hline $\mathrm{Ca}^{2+}$ channel & $\begin{array}{l}\text { Expression in } \\
\text { melanoma cells } \\
\text { relative to } \\
\text { melanocytes }\end{array}$ & Effects & References \\
\hline TRPM1 & $\begin{array}{c}\text { Very } \\
\text { low/undetectable }\end{array}$ & $\begin{array}{c}\text { Proapoptotic } \\
\text { Reduced metastatic potential } \\
\text { Reduced migration and invasion }\end{array}$ & {$[16,26,38-42]$} \\
\hline TPRM8 & Increased & Favored tumor progression & {$[17,43]$} \\
\hline TRPM2 & Increased & $\begin{array}{l}\text { Increased proliferation by } \\
\text { overexpression }\end{array}$ & {$[38,44]$} \\
\hline TRPM7 & Increased & Favored metastasis and invasion & {$[38,45]$} \\
\hline SOCE & Increased & $\begin{array}{c}\text { Prosurvival } \\
\text { Increased proliferation }\end{array}$ & {$[46-48]$} \\
\hline T-type & Increased & $\begin{array}{c}\text { Increased proliferation } \\
\text { Macroautophagy blocked by } \\
\text { pharmacological inhibition/gene } \\
\text { silencing }\end{array}$ & {$[36,49]$} \\
\hline
\end{tabular}

a central role in many cellular and physiological functions. Indeed, SOCE is the main mechanism that implicates $\mathrm{Ca}^{2+}$ import from extracellular to intracellular space, especially in nonexcitable cells [59]. In the SOCE pathway, STIM proteins detect the depletion of $\mathrm{Ca}^{2+}$ at the ER and respond by translocating to the plasma membrane, where they activate ORAI $\mathrm{Ca}^{2+}$ channels and allow $\mathrm{Ca}^{2+}$ influx.

However, the role of SOCE in melanoma has not been investigated extensively. One study suggested a functional relevance for $\mathrm{Ca}^{2+}$-driven growth and survival of melanoma cells due to the control of SOCE by mitochondria [46]. The authors showed that coupling of mitochondria to SOCE allows the maintenance of strong $\mathrm{Ca}^{2+}$ fluxes and sustains a constitutive activation of $\mathrm{PKB} / \mathrm{Akt}$ pathway, leading to an increased melanoma cell survival and resistance to apoptosis (Figure 1; Table 1). The same research group later demonstrated in vitro and in vivo that lipid rafts are critical for coupling SOCE to the constitutive activation of $\mathrm{PKB} / \mathrm{Akt}$ in a $\mathrm{Ca}^{2+} /$ calmodulin-, Src-, and PP2A-mediated pathway. These results underscore the potential of lipid raft disruptors as effective anticancer treatments [47].

More recently, Umemura et al. described that proliferation and migration are also regulated by SOCE in melanoma cells. They found that STIM1 and ORAI1 were expressed at high levels in human melanomas and melanoma cell lines. When SOCE activity was inhibited by pharmacological blockade or by siRNA-mediated gene knockdown, the proliferation rate was halted, cell migration was prevented, and metastasis progression was delayed (Figure 1; Table 1). Moreover, their results suggested that melanoma progression is promoted by SOCE through CaMKII/Raf-1/ERK signaling pathway, independently of BRAF mutations. Therefore, targeting SOCE could be a new strategy to treat a great number of melanoma patients, in monotherapy or in combination with BRAF inhibitors [48].

2.3. Voltage-Gated $\mathrm{Ca}^{2+}$ Channels (VGCCs) in Melanoma. In 2012, our research group reported that both normal melanocytes and transformed melanoma cells express functional VGCCs, including members of the $\mathrm{Ca}_{\mathrm{v}} 1$ (L-type), $\mathrm{Ca}_{\mathrm{v}} 2$ (N, P/Q or R-types), and $\mathrm{Ca}_{\mathrm{v}} 3$ (T-type) families [49]. However, differences were noticed between the different cell lines regarding the expression of particular isoforms. Remarkably, untransformed melanocytes expressed only very low levels of T-type $\mathrm{Ca}_{\mathrm{v}} 3.1$ channels, whereas transcripts for T-type $\mathrm{Ca}_{\mathrm{v}} 3.2$ and $\mathrm{Ca}_{\mathrm{v}} 3.3$ channels were undetectable. We also found a correlation between the proliferation rate and the expression of specific T-type channels isoforms, such that the melanoma cell lines displaying a high proliferation rate expressed higher levels of $\mathrm{Ca}_{\mathrm{v}} 3.2$ channels (Figure 1; Table 1), whereas those ones growing slowly expressed preferentially the $\mathrm{Ca}_{\mathrm{v}} 3.1$ isoform. Interestingly, the expression of these two T-type channel isoforms was counterbalanced. Furthermore, the results attained in gene knockdown experiments showed that whereas both $\mathrm{Ca}_{\mathrm{v}} 3.1$ and $\mathrm{Ca}_{\mathrm{v}} 3.2$ isoforms promote the progression of melanoma cells, the expression of $\mathrm{Ca}_{\mathrm{v}} 3.1$ is associated with slow cycling and it is induced under hypoxic conditions [49]. In a follow-up study, we described that clinically used T-type channel pharmacological blockers induced G1/S cell cycle arrest and also triggered the apoptotic death of melanoma cells, which was partially dependent on mitochondrial caspase activation [36]. An in-depth analysis of the process revealed that apoptosis is preceded by ER stress and subsequent inhibition of the autophagic flux, which we found to be constitutively activated in melanoma cells (Figure 1; Table 1). These effects were mimicked by knockdown of $\mathrm{Ca}_{\mathrm{v}} 3.1$ and $\mathrm{Ca}_{\mathrm{v}} 3.2$ channels, thus allowing the identification of these T-type channels as novel targets to deregulate autophagy and induce cytotoxicity in melanoma cells [36].

\section{Conclusions and Future Developments}

Recent advances in the understanding of how $\mathrm{Ca}^{2+}$ influx is involved in melanoma tumorigenesis and progression may provide new targeted therapies for melanoma treatment. For this to materialize, it is essential to further deepen the 
study of the role of plasma membrane $\mathrm{Ca}^{2+}$ channels in melanoma cell proliferation and also in other less explored areas, such as migration or survival. In light of current knowledge, the selective activation of certain TRP channel isoforms and/or the development of humanized inhibitory antibodies to extracellular domains of TRP channels arise as putative therapeutic strategies $[15,16,51]$. Also, the blockade of $\mathrm{Ca}^{2+}$ influx through the use of pharmacological SOCE blockers and/or raft-targeting agents appears as an interesting approach to tackle melanoma progression [47, 48]. Finally, we highlight the potential of T-type $\mathrm{Ca}^{2+}$ channels as novel prognosis markers and/or therapeutic targets in melanoma. In this regard, our studies have uncovered a dual role of Ttype $\mathrm{Ca}^{2+}$ channels in controlling melanoma cell proliferation and $\mathrm{Ca}^{2+}$ homeostasis, with an impact on adaptive cancer cell mechanisms like ER stress and macroautophagy that are often associated with chemotherapeutic or radiotherapeutic resistance $[36,49]$. Thus, existing $\mathrm{Ca}^{2+}$ channel blockers may expand the pharmacological arsenal and become valuable partners for combined chemotherapies against melanoma.

\section{Abbreviations}

ER: Endoplasmic reticulum

$\mathrm{Ca}^{2+}: \quad$ Ionized calcium

TRPM: Transient receptor potential melastatin

TRPV: Transient receptor potential vanilloid

TRPC: Transient receptor potential canonical

SOCE: Store-operated calcium entry

VGCCs: Voltage-gated calcium channels

BRAF: v-raf murine sarcoma viral oncogene homolog B1.

\section{Disclosure}

R. M. Martí and C. Cantí are co-senior authors.

\section{Conflict of Interests}

The authors declare that there is no conflict of interests regarding the publication of this paper.

\section{Acknowledgments}

This research was supported by grants from ISCIII (PI1200260 to R. M. Martí and PI1301980 to J. Herreros) and grant from Fundació la Marató de TV3 (subproject 201331-31 to R. M. Martí).

\section{References}

[1] T. A. Stewart, K. T. Yapa, and G. R. Monteith, "Altered calcium signaling in cancer cells," Biochimica et Biophysica Acta (BBA)Biomembranes, 2014.

[2] E. Carafoli, "The calcium-signalling saga: Tap water and protein crystals," Nature Reviews Molecular Cell Biology, vol. 4, no. 4, pp. 326-332, 2003.
[3] A. M. Hofer and E. M. Brown, "Extracellular calcium sensing and signalling," Nature Reviews Molecular Cell Biology, vol. 4, no. 7, pp. 530-538, 2003.

[4] C. R. Kahl and A. R. Means, "Regulation of cell cycle progression by calcium/calmodulin-dependent pathways," Endocrine Reviews, vol. 24, no. 6, pp. 719-736, 2003.

[5] T. Capiod, "The need for calcium channels in cell proliferation," Recent Patents on Anti-Cancer Drug Discovery, vol. 8, no. 1, pp. 4-17, 2013.

[6] A. L. Boynton, J. F. Whitfield, R. J. Isaacs, and R. G. Tremblay, "Different extracellular calcium requirements for proliferation of nonneoplastic, preneoplastic, and neoplastic mouse cells," Cancer Research, vol. 37, no. 8, pp. 2657-2661, 1977.

[7] N. Takuwa, W. Zhou, and Y. Takuwa, "Calcium, calmodulin and cell cycle progression," Cellular Signalling, vol. 7, no. 2, pp. $93-$ 104, 1995.

[8] G. Shapovalov, V. Lehen'kyi, R. Skryma, and N. Prevarskaya, "TRP channels in cell survival and cell death in normal and transformed cells," Cell Calcium, vol. 50, no. 3, pp. 295-302, 2011.

[9] B. Kumar, K. Dreja, S. S. Shah et al., "Upregulated TRPC1 channel in vascular injury in vivo and its role in human neointimal hyperplasia," Circulation Research, vol. 98, no. 4, pp. 557-563, 2006.

[10] W. Zhang, K. E. Halligan, X. Zhang et al., "Orail-mediated $I_{C R A C}$ is essential for neointima formation after vascular injury," Circulation Research, vol. 109, no. 5, pp. 534-542, 2011.

[11] L. L. Cribbs, "T-type $\mathrm{Ca}^{2+}$ channels in vascular smooth muscle: Multiple functions," Cell Calcium, vol. 40, no. 2, pp. 221-230, 2006.

[12] T. Kuga, S. Kobayashi, Y. Hirakawa, H. Kanaide, and A. Takeshita, "Cell cycle-dependent expression of L- and T-type Ca ${ }^{2+}$ currents in rat aortic smooth muscle cells in primary culture," Circulation Research, vol. 79, no. 1, pp. 14-19, 1996.

[13] G. R. Monteith, D. McAndrew, H. M. Faddy, and S. J. RobertsThomson, "Calcium and cancer: targeting $\mathrm{Ca}^{2+}$ transport," Nature Reviews Cancer, vol. 7, no. 7, pp. 519-530, 2007.

[14] G. R. Monteith, F. M. Davis, and S. J. Roberts-Thomson, "Calcium channels and pumps in cancer: changes and consequences," The Journal of Biological Chemistry, vol. 287, no. 38, pp. 31666-31673, 2012.

[15] M. Bödding, “TRP proteins and cancer," Cellular Signalling, vol. 19, no. 3, pp. 617-624, 2007.

[16] N. Prevarskaya, L. Zhang, and G. Barritt, "TRP channels in cancer," Biochimica et Biophysica Acta (BBA)_Molecular Basis of Disease, vol. 1772, no. 8, pp. 937-946, 2007.

[17] L. Tsavaler, M. H. Shapero, S. Morkowski, and R. Laus, “Trpp8, a novel prostate-specific gene, is up-regulated in prostate cancer and other malignancies and shares high homology with transient receptor potential calcium channel proteins," Cancer Research, vol. 61, no. 9, pp. 3760-3769, 2001.

[18] T. Capiod, "Cell proliferation, calcium influx and calcium channels," Biochimie, vol. 93, no. 12, pp. 2075-2079, 2011.

[19] X.-T. Wang, Y. Nagaba, H. S. Cross, F. Wrba, L. Zhang, and S. E. Guggino, "The mRNA of L-type calcium channel elevated in colon cancer: protein distribution in normal and cancerous colon," The American Journal of Pathology, vol. 157, no. 5, pp. 1549-1562, 2000.

[20] B. Dziegielewska, L. S. Gray, and J. Dziegielewski, "T-type calcium channels blockers as new tools in cancer therapies," Pflügers Archiv, vol. 466, no. 4, pp. 801-810, 2014. 
[21] P. Lory, I. Bidaud, and J. Chemin, "T-type calcium channels in differentiation and proliferation," Cell Calcium, vol. 40, no. 2, pp. 135-146, 2006.

[22] A. J. Ridley, M. A. Schwartz, K. Burridge et al., "Cell migration: integrating signals from front to back," Science, vol. 302, no. 5651, pp. 1704-1709, 2003.

[23] N. Prevarskaya, R. Skryma, and Y. Shuba, "Calcium in tumour metastasis: new roles for known actors," Nature Reviews Cancer, vol. 11, no. 8, pp. 609-618, 2011.

[24] J.-P. Chen, Y. Luan, C.-X. You, X.-H. Chen, R.-C. Luo, and R. $\mathrm{Li}$, “TRPM7 regulates the migration of human nasopharyngeal carcinoma cell by mediating $\mathrm{Ca}^{2+}$ influx," Cell Calcium, vol. 47, no. 5, pp. 425-432, 2010.

[25] J. Middelbeek, A. J. Kuipers, L. Henneman et al., "TRPM7 is required for breast tumor cell metastasis," Cancer Research, vol. 72, no. 16, pp. 4250-4261, 2012.

[26] L. M. Duncan, J. Deeds, J. Hunter et al., "Down-regulation of the novel gene melastatin correlates with potential for melanoma metastasis," Cancer Research, vol. 58, no. 7, pp. 1515-1520, 1998.

[27] Y.-F. Chen, Y.-T. Chen, W.-T. Chiu, and M.-R. Shen, "Remodeling of calcium signaling in tumor progression," Journal of Biomedical Science, vol. 20, article 23, 2013.

[28] S. Yang, J. J. Zhang, and X.-Y. Huang, "Orail and STIM1 are critical for breast tumor cell migration and metastasis," Cancer Cell, vol. 15, no. 2, pp. 124-134, 2009.

[29] Y.-F. Chen, W.-T. Chiu, Y.-T. Chen et al., "Calcium store sensor stromal-interaction molecule 1-dependent signaling plays an important role in cervical cancer growth, migration, and angiogenesis," Proceedings of the National Academy of Sciences, vol. 108, no. 37, pp. 15225-15230, 2011.

[30] N. Yang, Y. Tang, F. Wang et al., "Blockade of store-operated $\mathrm{Ca}^{2+}$ entry inhibits hepatocarcinoma cell migration and invasion by regulating focal adhesion turnover," Cancer Letters, vol. 330, no. 2, pp. 163-169, 2013.

[31] J.-B. Huang, A. L. Kindzelskii, A. J. Clark, and H. R. Petty, "Identification of channels promoting calcium spikes and waves in HT1080 tumor cells: their apparent roles in cell motility and invasion," Cancer Research, vol. 64, no. 7, pp. 2482-2489, 2004.

[32] Y. Zhang, J. Zhang, D. Jiang et al., "Inhibition of T-type $\mathrm{Ca}^{2+}$ channels by endostatin attenuates human glioblastoma cell proliferation and migration," British Journal of Pharmacology, vol. 166, no. 4, pp. 1247-1260, 2012.

[33] L. Zhang and G. J. Barritt, "Evidence that TRPM8 is an androgen-dependent $\mathrm{Ca}^{2+}$ channel required for the survival of prostate cancer cells," Cancer Research, vol. 64, no. 22, pp. 83658373, 2004.

[34] G. Bidaux, M. Flourakis, S. Thebault et al., "Prostate cell differentiation status determines transient receptor potential melastatin member 8 channel subcellular localization and function," Journal of Clinical Investigation, vol. 117, no. 6, pp. 1647-1657, 2007.

[35] M. Hartel, F. F. Di Mola, F. Selvaggi et al., "Vanilloids in pancreatic cancer: potential for chemotherapy and pain management," Gut, vol. 55, no. 4, pp. 519-528, 2006.

[36] A. Das, C. Pushparaj, J. Herreros et al., "T-type calcium channel blockers inhibit autophagy and promote apoptosis of malignant melanoma cells," Pigment Cell and Melanoma Research, vol. 26, no. 6, pp. 874-885, 2013.

[37] N. C. K. Valerie, B. Dziegielewska, A. S. Hosing et al., "Inhibition of T-type calcium channels disrupts Akt signaling and promotes apoptosis in glioblastoma cells," Biochemical Pharmacology, vol. 85, no. 7, pp. 888-897, 2013.
[38] H. Guo, J. A. Carlson, and A. Slominski, "Role of TRPM in melanocytes and melanoma," Experimental Dermatology, vol. 21, no. 9, pp. 650-654, 2012.

[39] D. Fang and V. Setaluri, "Expression and up-regulation of alternatively spliced transcripts of melastatin, a melanoma metastasis-related gene, in human melanoma cells," Biochemical and Biophysical Research Communications, vol. 279, no. 1, pp. 53-61, 2000.

[40] J. Deeds, F. Cronin, and L. M. Duncan, "Patterns of melastatin mRNA expression in melanocytic tumors," Human Pathology, vol. 31, no. 11, pp. 1346-1356, 2000.

[41] L. M. Duncan, J. Deeds, F. E. Cronin et al., "Melastatin expression and prognosis in cutaneous malignant melanoma," Journal of Clinical Oncology, vol. 19, no. 2, pp. 568-576, 2001.

[42] A. J. Miller, J. Du, S. Rowan, C. L. Hershey, H. R. Widlund, and D. E. Fisher, "Transcriptional regulation of the melanoma prognostic marker melastatin (TRPM1) by MITF in melanocytes and melanoma," Cancer Research, vol. 64, no. 2, pp. 509-516, 2004.

[43] H. Yamamura, S. Ugawa, T. Ueda, A. Morita, and S. Shimada, "TRPM8 activation suppresses cellular viability in human melanoma," The American Journal of Physiology-Cell Physiology, vol. 295, no. 2, pp. C296-C301, 2008.

[44] U. Orfanelli, A.-K. Wenke, C. Doglioni, V. Russo, A. K. Bosserhoff, and G. Lavorgna, "Identification of novel sense and antisense transcription at the TRPM2 locus in cancer," Cell Research, vol. 18, no. 11, pp. 1128-1140, 2008.

[45] M. S. McNeill, J. Paulsen, G. Bonde, E. Burnight, M.-Y. Hsu, and R. A. Cornell, "Cell death of melanophores in zebrafish trpm7 mutant embryos depends on melanin synthesis," Journal of Investigative Dermatology, vol. 127, no. 8, pp. 2020-2030, 2007.

[46] B. Feldman, S. Fedida-Metula, J. Nita, I. Sekler, and D. Fishman, "Coupling of mitochondria to store-operated $\mathrm{Ca}^{2+}$-signaling sustains constitutive activation of protein kinase B/Akt and augments survival of malignant melanoma cells," Cell Calcium, vol. 47, no. 6, pp. 525-537, 2010.

[47] S. Fedida-Metula, B. Feldman, V. Koshelev, U. Levin-Gromiko, E. Voronov, and D. Fishman, "Lipid rafts couple store-operated $\mathrm{Ca}^{2+}$ entry to constitutive activation of $\mathrm{PKB} / \mathrm{Akt}$ in a $\mathrm{Ca}^{2+} /$ calmodulin-, Src- and PP2A-mediated pathway and promote melanoma tumor growth," Carcinogenesis, vol. 33, no. 4, pp. 740-750, 2012.

[48] M. Umemura, E. Baljinnyam, S. Feske et al., "Store-operated $\mathrm{Ca}^{2+}$ entry (SOCE) regulates melanoma proliferation and cell migration," PLoS ONE, vol. 9, no. 2, Article ID e89292, 2014.

[49] A. Das, C. Pushparaj, N. Bahí et al., "Functional expression of voltage-gated calcium channels in human melanoma," Pigment Cell and Melanoma Research, vol. 25, no. 2, pp. 200-212, 2012.

[50] S. C. Weatherhead, M. Haniffa, and C. M. Lawrence, "Melanomas arising from naevi and de novo melanomas-does origin matter?" British Journal of Dermatology, vol. 156, no. 1, pp. 7276, 2007.

[51] D. Gkika and N. Prevarskaya, "Molecular mechanisms of TRP regulation in tumor growth and metastasis," Biochimica et Biophysica Acta-Molecular Cell Research, vol. 1793, no. 6, pp. 953-958, 2009.

[52] E. Oancea, J. Vriens, S. Brauchi, J. Jun, I. Splawski, and D. E. Clapham, "TRPM1 forms ion channels associated with melanin content in melanocytes," Science Signaling, vol. 2, no. 70, article ra21, 2009.

[53] S. Zhiqi, M. H. Soltani, K. M. R. Bhat et al., "Human melastatin 1 (TRPM1) is regulated by MITF and produces 
multiple polypeptide isoforms in melanocytes and melanoma," Melanoma Research, vol. 14, no. 6, pp. 509-516, 2004.

[54] S. Lu, A. Slominski, S.-E. Yang, C. Sheehan, J. Ross, and J. A. Carlson, "The correlation of TRPM1 (Melastatin) mRNA expression with microphthalmia-associated transcription factor (MITF) and other melanogenesis-related proteins in normal and pathological skin, hair follicles and melanocytic nevi," Journal of Cutaneous Pathology, vol. 37, no. 1, pp. 26-40, 2010.

[55] C. Levy, M. Khaled, D. Iliopoulos et al., "Intronic miR-211 assumes the tumor suppressive function of its host gene in melanoma," Molecular Cell, vol. 40, no. 5, pp. 841-849, 2010.

[56] G. M. Boyle, S. L. Woods, V. F. Bonazzi et al., "Melanoma cell invasiveness is regulated by miR-211 suppression of the BRN2 transcription factor," Pigment Cell and Melanoma Research, vol. 24, no. 3, pp. 525-537, 2011.

[57] J. Mazar, K. de Young, D. Khaitan et al., "The regulation of miRNA-211 expression and its role in melanoma cell invasiveness," PLoS ONE, vol. 5, no. 11, Article ID el3779, 2010.

[58] S.-J. Chen, W. Zhang, Q. Tong et al., "Role of TRPM2 in cell proliferation and susceptibility to oxidative stress," American Journal of Physiology - Cell Physiology, vol. 304, no. 6, pp. C548C560, 2013.

[59] J. W. Putney Jr., "Capacitative calcium entry: sensing the calcium stores," Journal of Cell Biology, vol. 169, no. 3, pp. 381-382, 2005. 


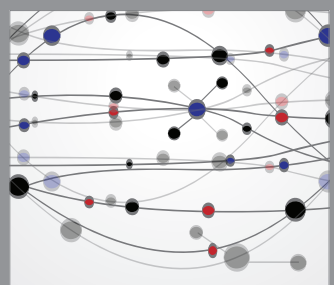

The Scientific World Journal
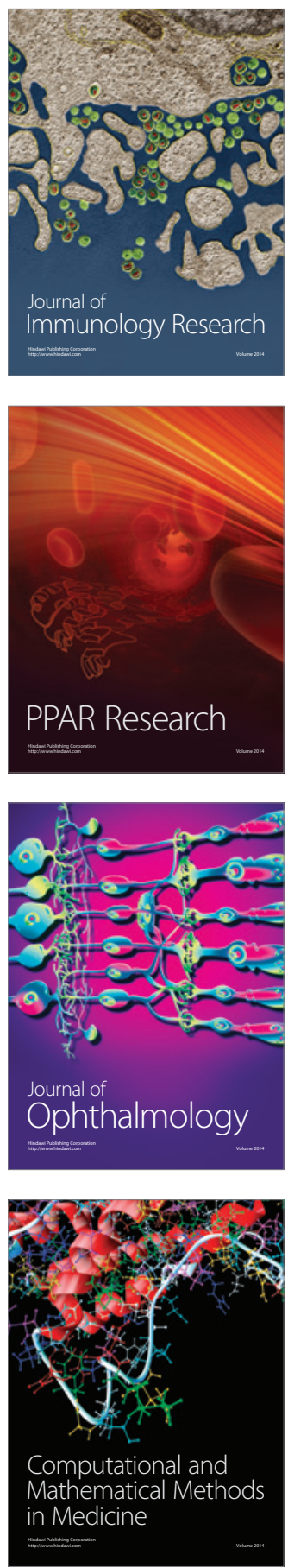

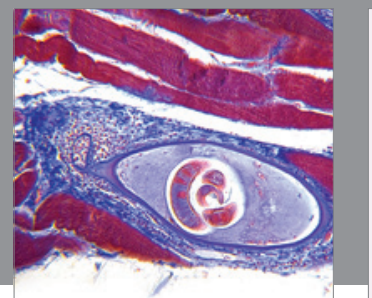

Gastroenterology

Research and Practice
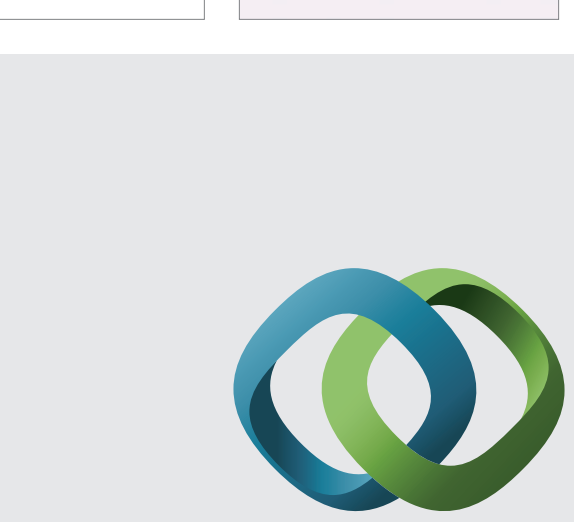

\section{Hindawi}

Submit your manuscripts at

http://www.hindawi.com
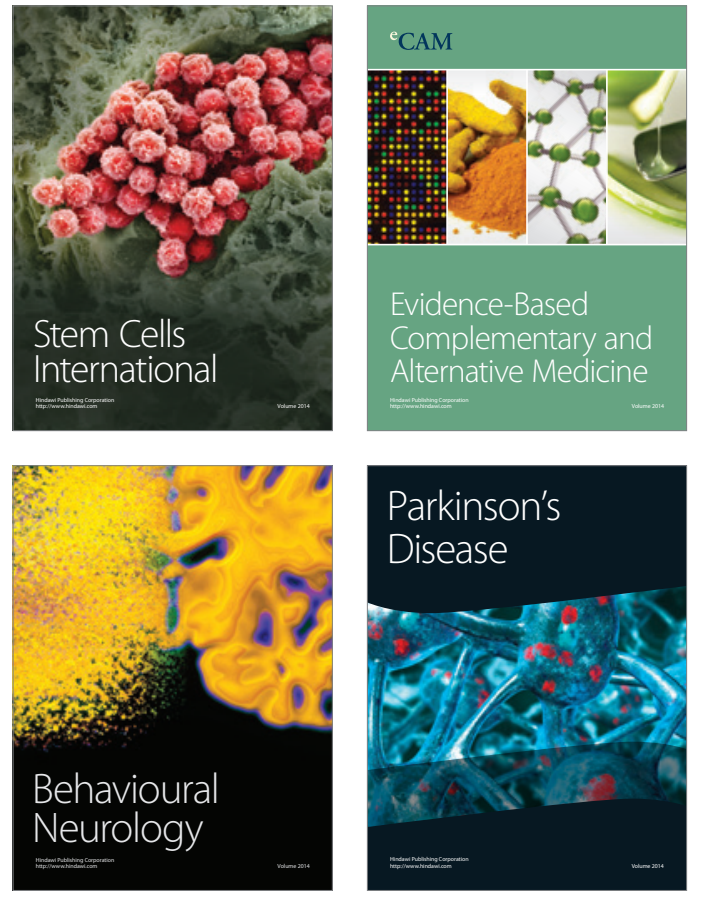
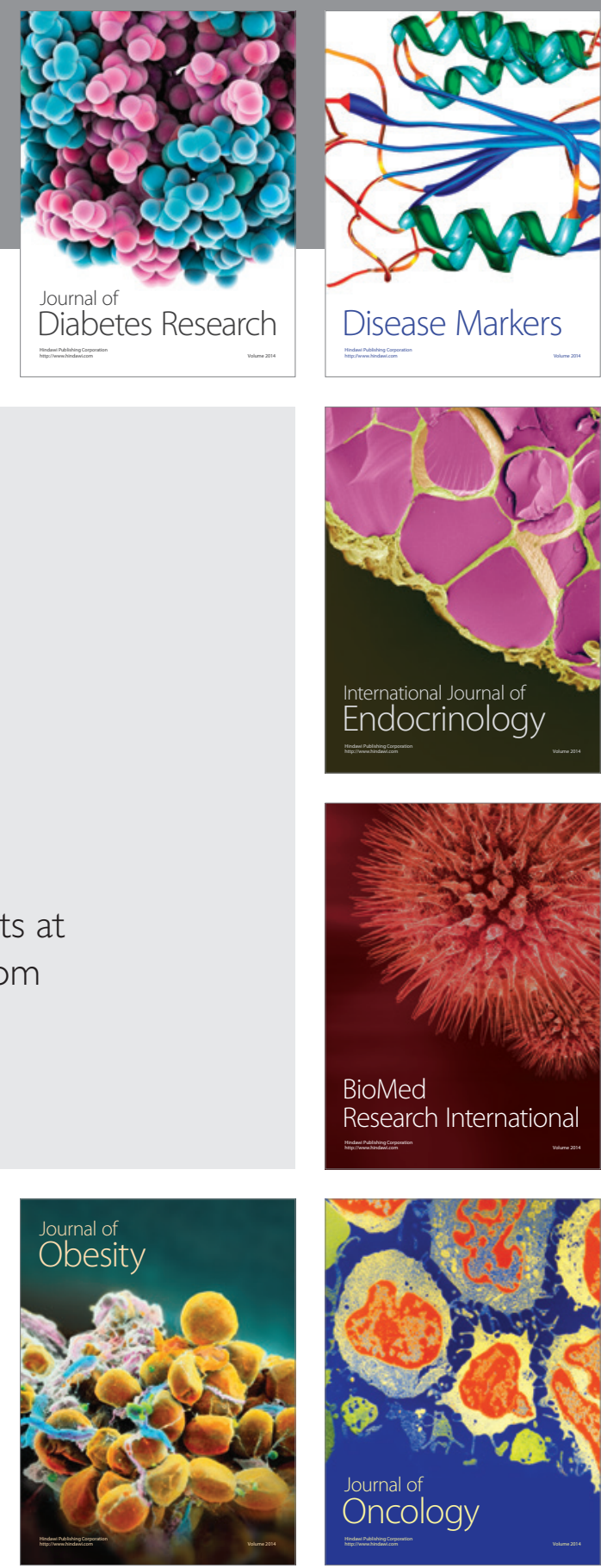

Disease Markers
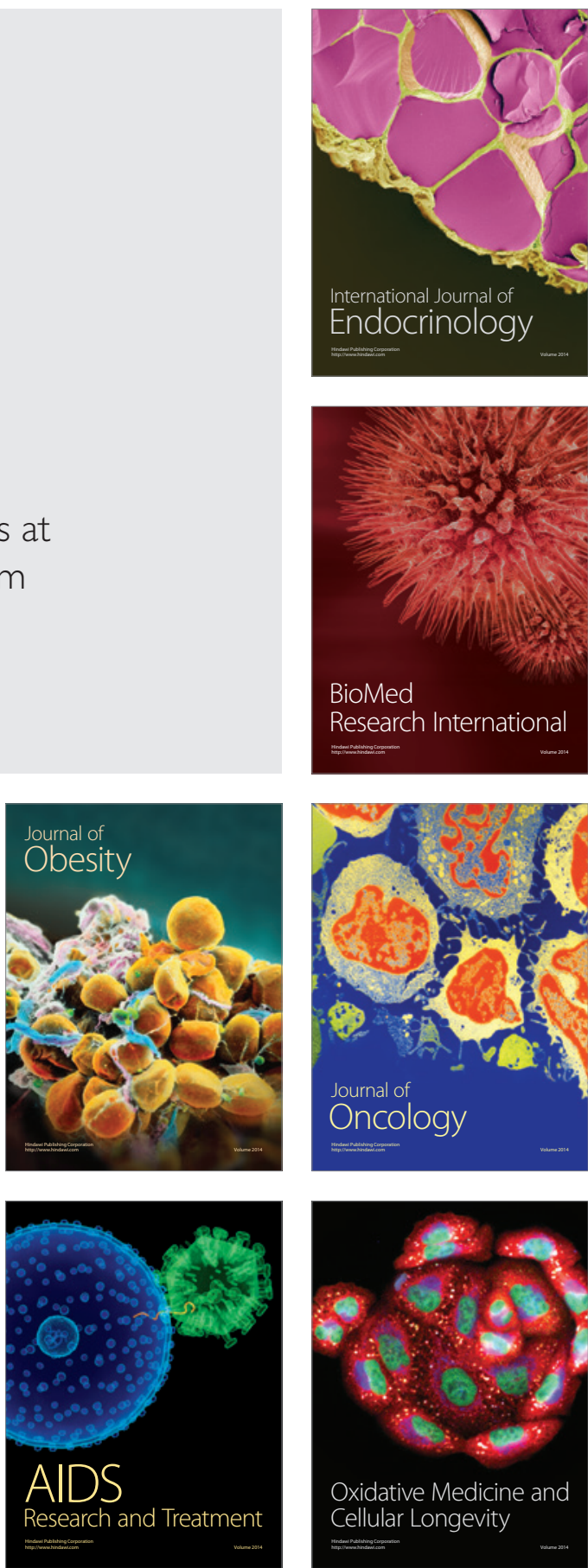